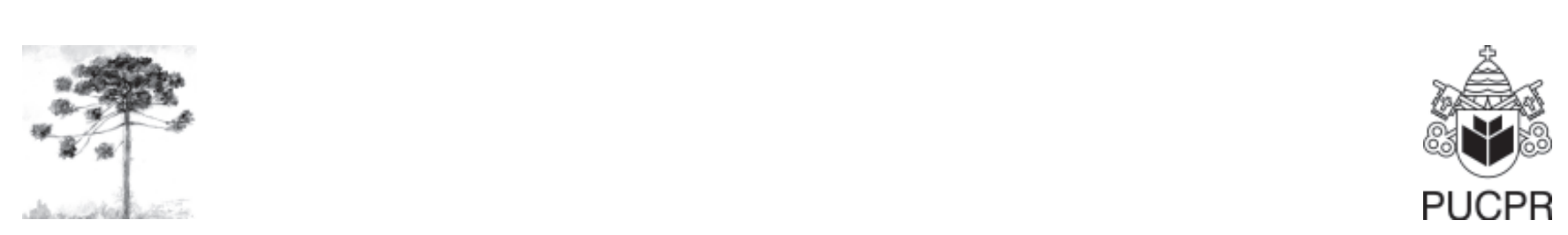

\title{
OCORRÊNCIA DE ESPÉCIES EXÓTICAS NA COMUNIDADE DO JAIRÉ NO RIO RIBEIRA DE IGUAPE
}

\author{
Exotic species occurrence in Jairé community in Ribeira de Iguape River
}

\author{
Edison Barbieri ${ }^{[1]}$, Jocemar Tomasino Mendonça ${ }^{[2]}$, Eduardo Tavares Paes ${ }^{[3]}$ \\ ${ }^{[1]}$ Professor e Pesquisador do Instituto de Pesca, APTA - SAA/SP, São Paulo, SP - Brasil, e-mail: edisonbarbieri@yahoo.com.br \\ ${ }^{[2]}$ Pesquisador do Instituto de Pesca, APTA - SAA/SP, São Paulo, SP - Brasil. \\ ${ }^{[3]}$ Pesquisador do Instituto de Pesquisas Espaciais (INPE), São Paulo, SP - Brasil.
}

\section{Resumo}

O Vale do Ribeira de Iguape apresenta uma grande produtividade de piscicultura, bem como de pesca, tanto de água doce como marinha. Durante o ano de 1999 foram analisados os desembarques pesqueiros na comunidade do Jairê, a fim de verificar a composição das capturas e incidência de espécies exóticas na pesca profissional do Rio Ribeira de Iguape. Na pesca de água doce destacamse as capturas de manjuba (Anchoviella lepidentostole); sardinha (Opishtonema oglinum) e traíra (Hoplias ssp.). Dentre a produção anual, $8 \%$ foi de espécies exóticas, sendo encontrado o curimbatá (Prochiladus scrofa), bagre africano (Clarias ssp.), pacu (Piaractus mesopotamicus), carpa (Ciprinus capio) e tilápia (Oriocromis niloticus). Esses peixes exóticos são oriundos dos escapes dos tanques de cultivo da região, provocado pelas cheias dos rios. Os peixes exóticos no ambiente natural podem causar impactos para as espécies nativas, como a copetição, predação, exclusão, além de hibridação. Assim sendo, é necessário um maior rigor na liberação da construção dos tanques de cultivo próximos à margem dos rios, evitando serem atingidos pelas cheias para não causar prejuízos tanto para o piscicultor como para o ecossistema como um todo. Uma vez que já ocorre uma significativa presença de peixes exóticos na pesca profissional artesanal do Rio Ribeira de Iguape.

Palavras-chave: Espécies exóticas; Rio; Ribeira de Iguape; Jairé.

\section{Abstract}

The Vale do Ribeira de Iguape it presents a great aquiculture productivity, as well as of fishing, so much of fresh water as marine. During the year of 1999 it was analyzed the fishing landings 
in the community of Jairê, in order to verify the composition of the captures and incidence of exotic species in the professional fishing of the river Ribeira de Iguape. In the fishing of fresh water to stands out the manjuba captures (Anchoviella lepidentostole); sardinha (Opishtonema oglinum) e traira (Hoplias ssp.). In the annual production, $8 \%$ were of exotic species, being found the curimbatá (Prochiladus scrofa), babre africano (Clarias ssp.), pacu (Piaractus mesopotamicus), carpa (Ciprinus carpio) and tilápia (Oriocromis niloticus). These exotic fish are originating from of the escapes of the aquaculture tanks of the area, carted by the full of the rivers. The exotic fish in the natural environment can bring problems as the predation and exclusion, besides hybridization with the native species. We suggested like this that it is seen the liberation of the construction better of the close cultivation tanks to the margin of the rivers, avoiding be reached by the full ones and like this not causing damages so much for the aquaculture farmed as for the ecosystem, because it already happens a significant presence of exotic fish in the professional fishing of the Ribeira de Iguape River.

Keywords: Exotic species; River; Ribeira de Iguape; Jairé.

\section{INTRODUÇÃO}

Uma das primeiras ocasiões em que a opinião pública se interessou pela alteração do ecossistema por espécies exóticas foi no aparecimento da mixomatose. Essa doença viral foi introduzida pelo francês Delille em coelhos que estavam se reproduzindo demais e danificando a colheita em sua propriedade. A virose se propagou rapidamente pela França e Espanha, dizimando de modo rápido as populações de coelhos. Ao introduzir a mixomatose, o homem alterou o equilíbrio cíclico entre o número de presas e de predadores. $\mathrm{Na}$ Espanha o Coelho era a presa principal do lince e da águia imperial, que tiveram suas populações seriamente afetadas pela falta de coelhos (1).

A introdução de espécies exóticas em um ecossistema pode provocar mudanças profundas no ambiente, criando competição com as espécies nativas. Exemplo deste fato foi a introdução de coelhos na Austrália, que provocou a diminuição de mamíferos nativos da região, como os cangurus, por causa da alteração do hábitat. Os estudos sobre espécies exóticas têm acompanhado o homem ao longo de sua história (2). Entretanto, os problemas causados pelas invasões de espécies exóticas vêm aumentando, e começam a se tornar um fenômeno com consequências mundiais (3). A alta frequência deinvasão está associada em grande parte às atividades humanas $(1,2)$, como por exemplo: transportes intercontinentais por navios e aviões, a aquicultura e a aquariofilia mal planejadas e sem fiscalização.
São consideradas espécies exóticas os organismos ou materiais biológicos (sementes, ovos, esporos, etc.) capazes de propagar animais e plantas e que tenham entrado em um ambiente onde antes não existiam. Várias são as consequências da introdução de espécies alóctones e exóticas no ambiente aquático, podendo ocorrer extirpação, predação e exclusão pela competitividade com as espécies nativas, bem como a hibridação $(2,4)$, causando impactos ao ecossistema e problemas à pesca em geral. Por esses motivos, a comunidade científica tem se voltado, nos últimos anos, para a questão da introdução de espécies exóticas, em função dos impactos ecológicos e econômicos decorrentes da invasão de vários ecossistemas, por animais e plantas exóticos (5). Porém a questão das invasões biológicas já ultrapassa os interesses acadêmicos, tornando-se uma questão de saúde pública (6).

O presente trabalho analisa as capturas da comunidade do Jairê situada na cidade de Iguape, Estado de São Paulo, com ênfase na presença de espécies alóctones e exóticas que foram capturadas.

\section{METODOLOGIA}

\section{Área de estudo}

A região do Vale do Ribeira apresenta uma grande produtividade de pescado cultivado, sendo estimada em mais de duas mil toneladas/ano, segundo 
a Cooperativa de Piscicultores do Vale do Ribeira. As espécies mais comuns utilizadas para a psicultura na região são a tilápia (Oriocromis niloticus), bagre africano (Clarias sp.), carpa (Cyprinus carpio), pacu (Piaractus mesopotamicus) e curimbatá (Prochiladus scrofa).

Historicamente, o Vale do Rio Ribeira na região de Iguape está sujeito a enchentes, ocorrendo frequentemente o transbordamento dos tanques, provocando o escape de peixes utilizados em cultivos para os rios da região. Os indivíduos que escapam vão principalmente para o Rio Ribeira de Iguape, onde ocorre a pesca profissional artesanal, na qual o produto base é a manjuba (Anchoviella lepidentostole), compondo mais de $70 \%$ dos desembarques no município de Iguape, podendo atingir mais de 5 mil toneladas (7).

A comunidade do Jairê tem a pesca como principal atividade, sendo direcionada para a captura da manjuba nos meses de verão e as espécies de água doce como alternativa durante a entressafra.
Com a pesca de peixes de água doce, ocorrem diversas capturas de espécies alóctones e exóticas, sendo muitas vezes o principal produto da captura.

\section{METODOLOGIA}

O trabalho foi desenvolvido no período de setembro de 1998 a dezembro de 1999, na comunidade do Jairê, município de Iguape, no litoral sul do Estado de São Paulo (Figura 1). Realizaramse visitas quinzenais ao bairro, para a coleta de dados de produção e aspectos socioeconômicos, através dos pontos de escoamento e com entrevistas diretas com os pescadores. No ano de 1998, as coletas estavam sendo iniciadas, assim sendo, foi utilizado esse período para ajustar o sistema de coleta de dados de produção de acordo com Mendonça (8).

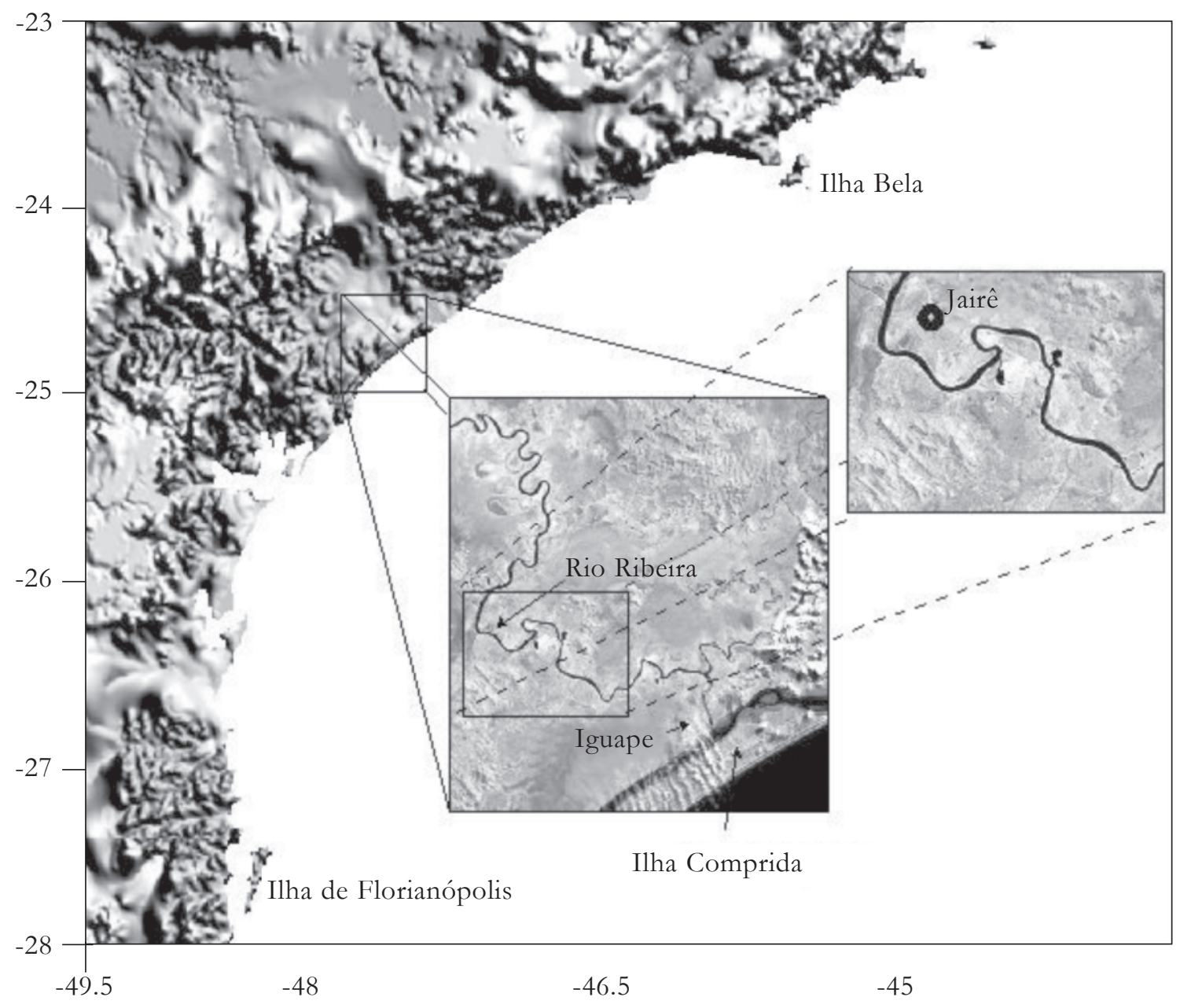

FIGURA 1 - Mapa do relevo do litoral sudeste brasileiro destacando a localização do estudo e do Rio Ribeira de Iguape 
As categorias de pescado foram divididas de acordo com a classificação utilizada na comercialização dos produtos pelos pescadores. Definiu-se como espécies nativas os indivíduos naturais do Rio Ribeira de Iguape e adjacências, espécies alóctones provenientes de outras bacias do mesmo país e, ainda, espécies exóticas provenientes de outros países.

A produtividade da piscicultura do Vale do Ribeira foi inferida através de dados de aquisição de alevinos da Cooperativa de Piscicultores do Vale do Ribeira, a qual conta com mais de $60 \%$ dos produtores da região. Estimou-se, assim, a produção de peixes cultivados no Vale de acordo com a conversão de sobrevivência de alevinos e produtividade dos tanques.

\section{RESULTADOS}

A pesca artesanal é a principal atividade econômica do Bairro do Jairê, envolvendo um total de 81 pescadores. Em 1999 a produção total atingiu 54 toneladas, sendo as espécies mais desembarcadas a manjuba (Anchoviella lepidentostole) (43\% das capturas); sardinha (Opishtonema oglinum) (15\%); traíra (Hoplias ssp.) (10\%); saguá (Genyatremus luteus) (10\%); curimbatá (Prochiladus scrofa) (7\%) e nundiá (Rhandiassp.) (2\%) (Figura 2). O produto geralmente é comercializado "in natura" e quando há algum processamento, este se limita à salga, principalmente de manjuba, sardinha e ovas de sardinha.

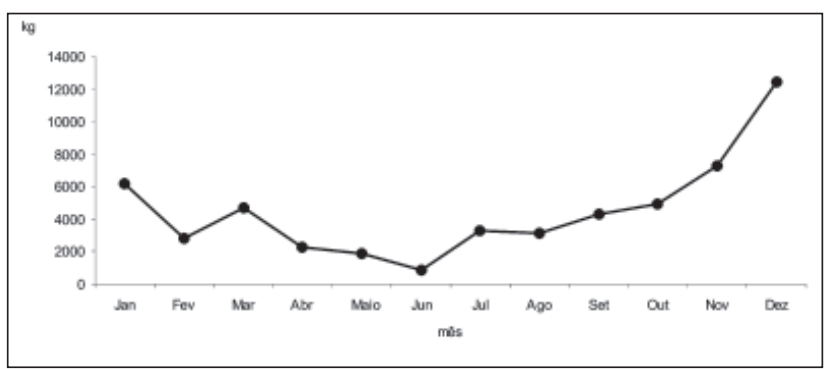

FIGURA 2 - Produção mensal das capturas de peixes na comunidade do Jairê no ano de 1999

As artes de pesca mais utilizadas para captura de manjuba são a manjubeira e o corrico (7). Estas artes capturam também outros peixes, como o robalo, saguá, sardinha, curimbatá, entre outros. Utilizam, também, redes de emalhar de fundo visando capturar traíras, curimbatá, bagres, saguá, entre outros. Outras artes utilizadas são o espinhel horizontal, principalmente para captura de bagres, jundiá e traíras. Entretanto, utiliza-se também covos para as capturas de crustáceos (pitu, lagosta elagostim), confeccionados com filetes de bambu dispostos às margens do rio. As capturas são marcadas pela safra da manjuba, quando ocorrem os maiores desembarques (Figura 3), no período de setembro a abril. Fora desse período, os principais produtos passam a ser o saguá, sardinha e traíra. A comunidade destaca-se por ser a principal fonte de recurso pesqueiro de água doce do município.

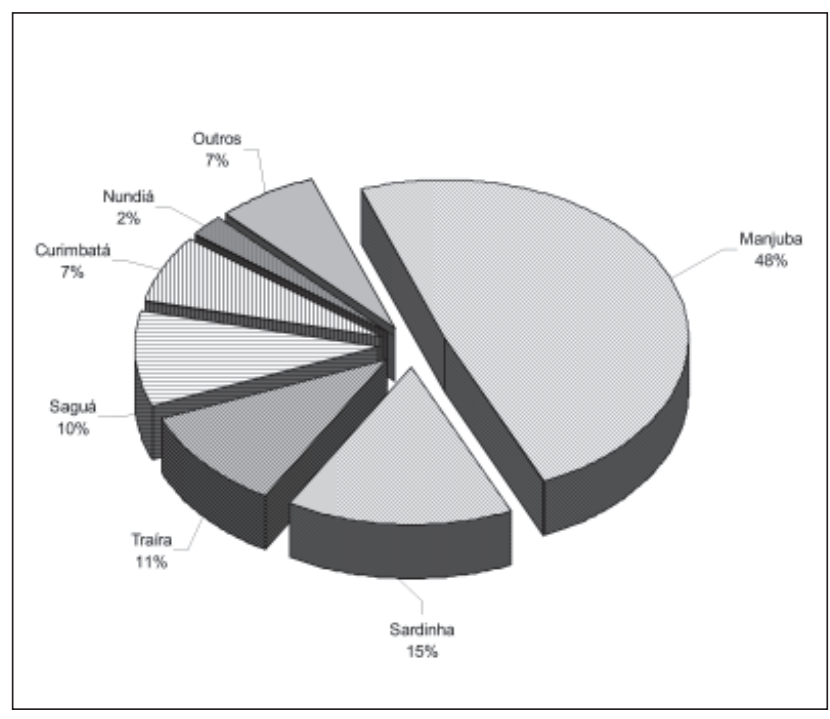

FIGURA 3 - Percentagem de ocorrência das principais espécies capturadas na comunidade do Jairê no ano de 1999

A captura de espécies alóctones e exóticas em 1999 ultrapassou 4,5 toneladas, perfazendo 8\% do total dos desembarques. As espécies alóctones que mais ocorreram foram curimbatá e pacu; enquanto que as espécies exóticas foram o bagre africano, carpa e tilápia (Figura 4). O curimbatá ocorreu em dois comprimentos, denominados de curimbinha, quando possuem comprimentos inferiores a $25 \mathrm{~cm}$, e curimbatá, quando acima desse comprimento.

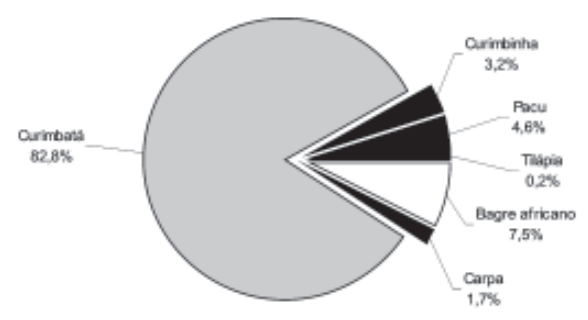

FIGURA 4 - Percentagem de ocorrência de peixes alóctones e exóticos na comunidade do Jairé em 1999 
Em 1999, os períodos em que ocorreram maiores desembarques foram entre janeiro e março, em julho e em dezembro (Figura 5). Entre janeiro e março e dezembro o predomínio foi de curimbatá, já em julho o bagre africano e curimbatá foram predominantes. Estes peixes ocorreram em todas as artes de pesca, sendo capturados de acordo com seus hábitats, ou seja, curimbatá, carpa, pacu e tilápia nas redes manjubeiras, corrico em redes de emalhar, e o bagre africano geralmente foicapturado em espinhéle redes de emalhar.

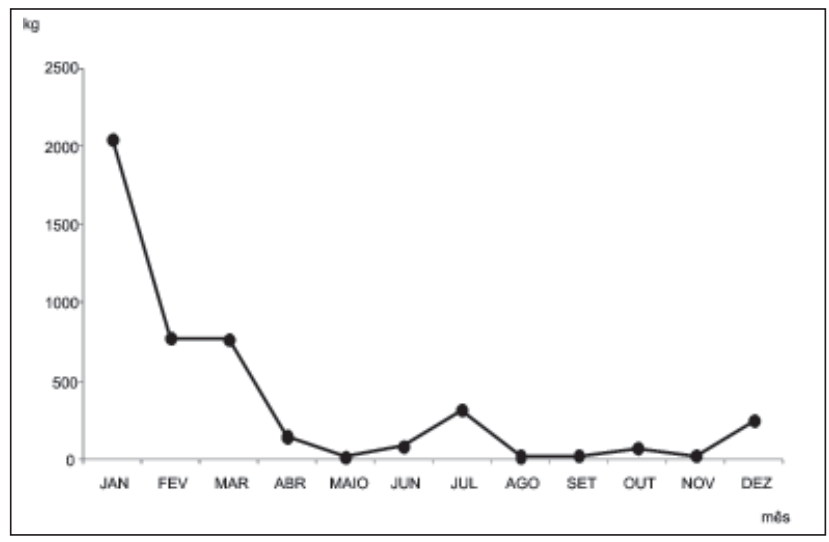

FIGURA 5 - Produção mensal, em kg, de espécies exóticas e alóctones na comunidade do Jairê

Houve maior captura das espécies exóticas e alóctones quando ocorreram as maiores variações mensais dos valores de anomalia de vazão, no período de agosto de 1998 a dezembro de 1999 (Figura 6). Ao analisarmos a relação entre espécies exóticas e alóctones com as anomalias de vazão, constatamos que houve uma forte correlação (Figura 7). O que resultou em maior captura dos não nativos nos meses de janeiro a março, período com maiores índices pluviométricos na região (Figura 8).

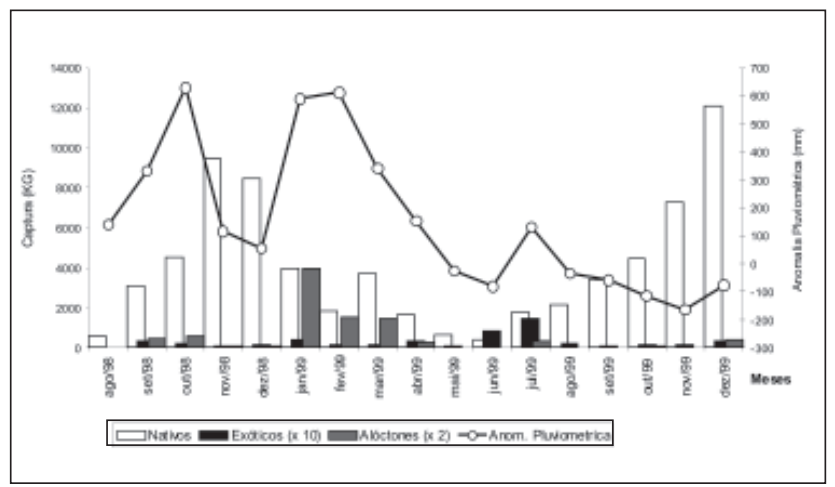

FIGURA 6 - Variações mensais dos valores de anomalia de vazão e captura das espécies de peixes nativas, exóticas e alóctones, no período de agosto de 1998 a dezembro de 1999

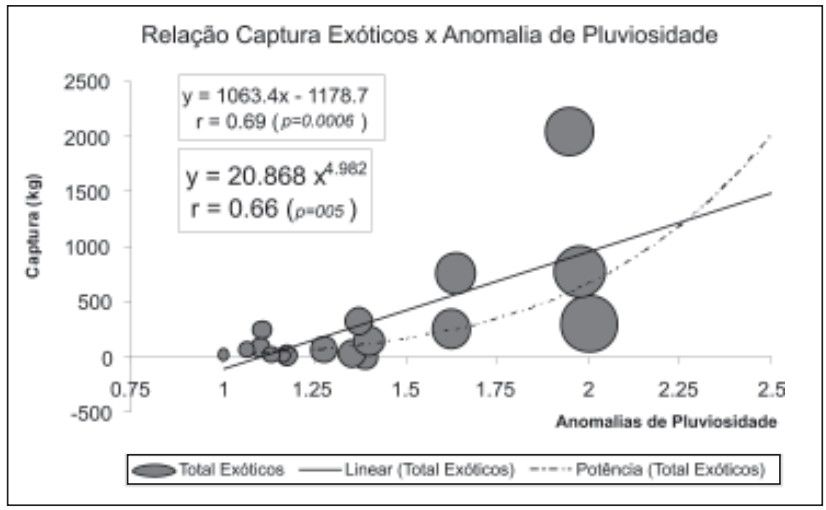

FIGURA 7 - Relação entre as espécies não nativas $\mathrm{x}$ anomalias de vazão. Círculos em cinzas referem-se à vazão realmedidaem $\mathrm{m}^{3} /$ mês. Escaladoeixoxrepresenta as anomalias da vazão ( $\mathrm{m}^{3} /$ mês) padronizadas
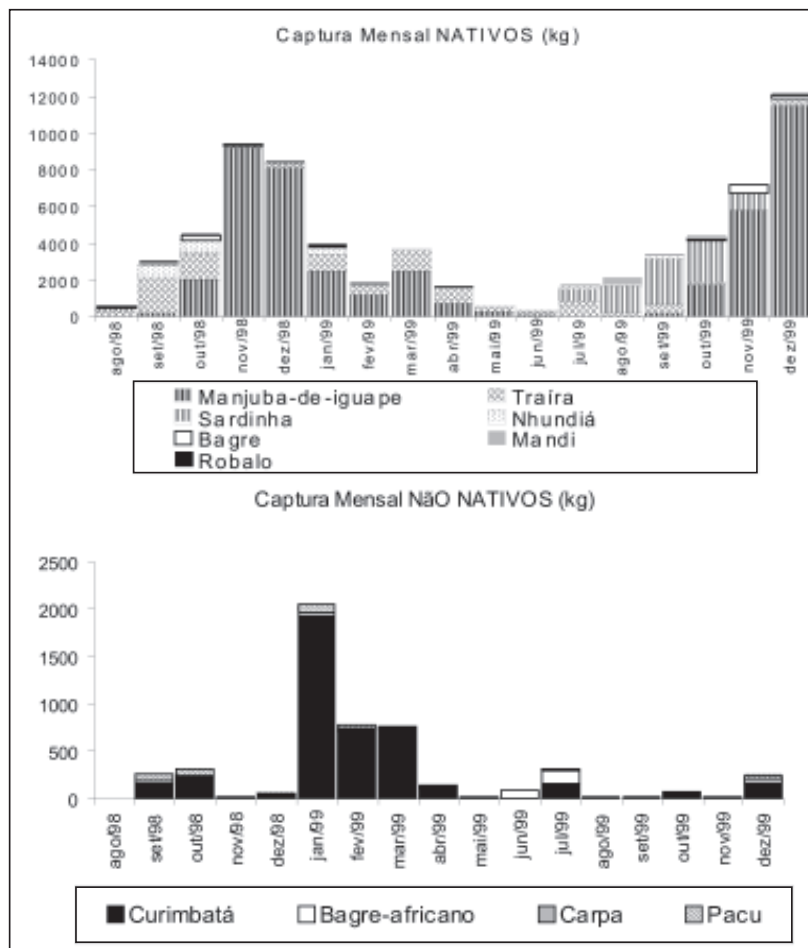

Distribuiçăo Porcentual NATINOS, ALÓCTONES E EXÓTICOS

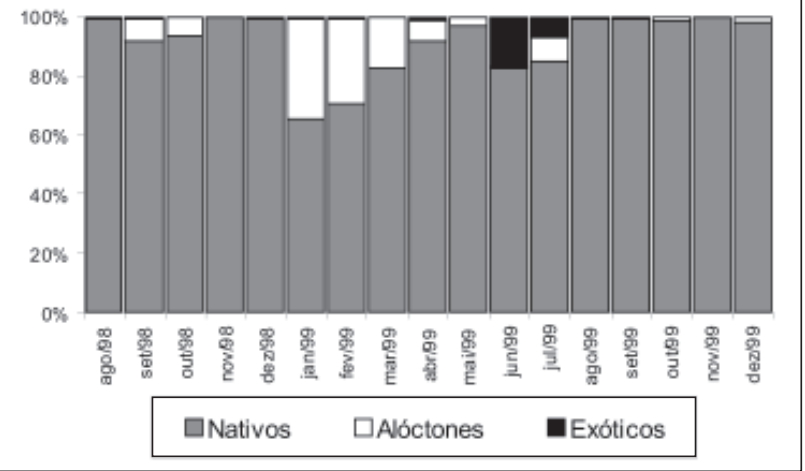

FIGURA 8 - Valores mensais das capturas das espécies nativas e nãonativas, eporcentagens capturadasmensalmente por categoria: nativas, não nativas e exóticas 


\section{DISCUSSÃO}

A comunidade do Jairê tem como característica mais importante ser o principal ponto de desembarque de pescado de água doce do município de Iguape. Os produtos mais desembarcados foram:manjuba, traíra, saguá, sardinha e curimbatá. A presença de peixes alóctones e exóticos nos desembarques foi considerada $(8 \%$ da produção total), composta de curimbatá, bagre africano, pacu, carpa e tilápia. Essas espécies ocorrem no Rio Ribeira, por causa das cheias que invadem os tanques de cultivo, instalados próximo às margens dos rios. Os peixes alóctones e exóticos no ambiente natural podem causar impactos às espécies nativas como a predação, competição e exclusão, além de hibridação (4). Tal fato ainda não pode ser observado, mas, de acordo com relatos dos pescadores, a produção de espécies nativas ao longo dos anos tem diminuído, e as espécies exóticas têm apresentado incremento nas capturas. Não é possível afirmar que as diminuições tenham sido diretamente influenciadas pela presença das espécies exóticas no Rio Ribeira, pois a sobrepesca na região é intensa. Entretanto, Howe et al. (9) indicaram impacto significativo do peixe Gambusia bolbrooki no crescimento e na reprodução do peixe nativo (Pseudomugil signifer) na África e na Ásia.

Espécies alóctones e exóticas podem tornar-se invasoras de diversos ambientes, com características de alta taxa de reprodução, rápida dispersão e grande tolerância a variações ambientais (3). Possivelmente sejam estes os motivos de haver grandes desembarques de curimbatá na comunidade, visto que a produção de janeiro de 1999 atingiu 1,9 toneladas desembarcadas. O curimbatá é natural da Bacia do Prata, sendo introduzido por piscicultores no Vale do Ribeira, não existindo referência de ser natural da região (10). Esta espécie já está se reproduzindo no ambiente, visto que ocorrem duas categorias de tamanhos, indicando duas coortes. Leite et al. (11) inferiram que a espécie apresenta alta produtividade, pertencente a um nível trófico bem baixo na pirâmide alimentar, corroborando com o encontrado nos desembarques da comunidade do Jairê. Os nossos dados indicam uma boa adaptação do corimbatá à bacia do Rio Ribeira de Iguape.

A tilápia, além de possuir características semelhantes às do corimbatá, quanto a adaptação ao ambiente também são tolerantes às variações de salinidade (12). Analisando tal potencial de dispersão e o incremento do cultivo desta espécie de acordo com as estimativas da Cooperativa de Piscicultores do Vale do Ribeira. A tilápia tornase, assim, uma das espécies de grande potencial de ocorrência na pesca profissional do Rio Ribeira, podendo futuramente trazer sérios problemas. A tilápia é uma espécie ornívora que revolve o fundo podendo alterar o hábitat, causar a extinção ou, no mínimo, a redução da população de espécies nativas.

O pacu tem processo semelhante às outras duas espécies, uma vez que possui um nível trófico baixo e de grande procura para o cultivo na região, com uma produção de mais de 200 toneladas nos tanques. Como é uma espécie com alta fecundidade, rusticidade (13) e com grande amplitude deitens alimentares (além de ser muito procurado pelos piscicultores, por seu alto valor comercial), faz com que apresente grande potencial de escape (principalmente nas cheias) e rápida adaptação ao ambiente natural.

O bagre africano foi introduzido no Brasil vindo da África, sendo uma espécie altamente tolerante a grandes variações ambientais, essa espécie pode atravessar de um tanque a outro rastejando-se pelo solo seco, característica que lhe confere grande característica dispersora, além de ser uma espécie com vários itens alimentar.

A introdução de espécies exóticas pode causar grandes impactos à biota e ao ecossistema como um todo. Exemplos como o do peixe Gambusia bolbrooki, que foi introduzido na Austrália para controlar a incidência de um mosquito, apresentou grande aumento de sua população e atualmente estudos apontam que é o responsável pela extinção de várias espécies de peixes da África e Ásia (9).

Os problemas econômicos causados por espécies exóticas vêm sendo documentados em muitos estudos, como por exemplo o do mexilhãozebra (Dreissema polymorpha) nativo da Europa, que invadiu e se estabeleceu nos Grandes Lagos, ao norte dos Estados Unidos, provocando gastos de milhões de dólares por ano para sua remoção e controle Carton (13). O ctenóforo (Mnemiopsis leidyı) endêmico da costa atlântica na América do Norte teve sua primeira ocorrência registrada nos mares Negro e de Azov, ao sul da Ucrânia e da Rússia, em 1982. Hoje a espécie está estabelecida nesses mares interiores e ocorre em massa. Os ctenófaros nativos foram totalmente extintos e a pesca de enchovas e espadartes na região caiu drasticamente. Em 1992, a espécie invasora foi registrada também no Mar 
Mediterrâneo (5). A introdução na Austrália de uma estrela-do-mar (Asterias amurensis) e de outras espécies como a alga Undaria pinnatifida (oriundos do Japão), o caranguejo Carcinus maenas, o verme poliqueto Sabella spallanzani (oriundos da Europa) e dinoflagelados tóxicos dos gêneros Gymnodinium e Alexandrium (oriundos do Japão) prejudicou a pesca e a aquicultura industrial (4).

$\mathrm{Na}$ costa brasileira já existe registro da introdução de pelo menos três espécies de caranguejos e cinco de camarões destes, só o caranguejo-aranha (Pyromaia tuberculata), originário da Califórnia, se estabeleceu no Brasil. Já foi detectado também no Rio de Janeiro, em São Paulo e no Paraná (5)

O mais recente caso de invasão com sucesso no Brasil é a do mexilhão-dourado (Limnoperna fortune $)$. $\mathrm{O}$ problema causado por esse organismo assemelha-se aos descritos para o mexilhão zebra. Por se incrustar em tubulações, L. fortunei já está causando problemas em unidades da usina hidrelétrica de Itaipu, confirmando, assim, que esse organismo já invadiu o Brasil e está se estabelecendo.

As espécies introduzidas podem trazer parasitas, bactérias e vírus patógenos aos quais as espécies nativas podem não ser imunes. A ostra japonesa Cassostrea gigas pode ter sido a origem da virose que dizimou a população de ostras autóctones Cassostrea angulata, na costa da Espanha e França (3). Seja acidental ou proposital a introdução de espécies alóctones e exóticas podem trazer patógenos para outras espécies, competição pelo mesmo hábitat ou recurso com as espécies nativas, além da contaminação genética, impactando desta forma todo o ecossistema envolvido. Um importante aspecto em estudos de ecologia e dinâmica de populações com espécies invasoras é a relação desta com o ecossistema preexistente. As espécies invasoras sempre interagirão com as espécies nativas, seja por predação ou competição, resultando ou não em extinção local. As espécies nativas e as invasoras podem competir por espaço ou alimento, ocasionando as extinções, ou a espécie invasora pode aproveitar um nicho vago e manter um equilíbrio com as nativas (6). Entretanto, relacionar espécies invasoras como ameaças ou pragas, pode ser apenas uma leitura superficial de um processo ecológico maior. Segundo Williamson (4), de cada dez espécies que chegam a um novo ambiente, por introdução humana, uma se torna invasora, e de cada dez invasoras, uma se estabelece, e de cada dez estabelecidas, uma se torna praga. A clássica visão ecológica de que as grandes mudanças em populações naturais abalariam o equilíbrio do planeta vem sendo modificada nos dias de hoje por novos estudos e definição de termos como equilíbrio de populações. A ideia de natureza estática vem dando lugar a uma nova visão mais dinâmica, onde são aceitáveis as mudanças em escalas de tempo menores $(6,14,15)$.

É impossível prever quais impactos terão a introdução de uma espécie não nativa ao ecossistema ou à saúde ambiental como um todo. Mesmo uma espécie que não mostra impactos negativos em sua área de origem pode ter efeitos dramáticos quando invadem novos ambientes. Logo, não é possível identificar áreas de risco zero, porém, segundo Margalef $(16,17)$ ecossistemas com maior diversidade de espécies, com uma teia mais densa e interconectada, tendem a ser mais resistentes a invasões que aqueles com menor diversidade (18). Pois em ambiente com grande diversidade de espécies, as mesmas tendem a ser eficientes competidoras.

Deveria haver uma melhor avaliação da liberação para construção dos tanques de cultivo próximos à margem dos rios, evitando serem atingidos pelas cheias, para não causar prejuízos tanto para o piscicultor como para o ecossistema, visto que já ocorre uma significativa presença de peixes exóticos na pesca profissional e artesanal do Rio Ribeira de Iguape. Necessita-se também de maiores estudos e um monitoramento constante da atividade pesqueira do Rio Ribeira para avaliar melhor a influência das espécies exóticas no ecossistema e na pesca da região como um todo. Necessita-se, também, uma determinação precisa das modalidades de descontaminação ou de quarentena para os organismos de interesse na aquicultura que são transportados; estas normas devem basear-se em rigorosos estudos científicos e não apenas responder ao controle sanitário.

A introdução voluntária de espécies, como na aquicultura, deve reger-se por um regulamento muito restritivo, justificando a necessidade de se utilizar tal espécie e não outras autóctones; valorar economicamente os benefícios desta introdução e apresentar estudos de impacto ambiental. Além desses procedimentos, a venda, transporte e manipulação de espécies exóticas em aquários e laboratórios científicos deveriam estar submetidos a regras de funcionamento também muitos restritivas (15). Por fim, a informação e a sensibilização do público sobre os riscos da introdução de espécies exóticas constitui o complemento indispensável a todo o esforço em matéria de legislação. 


\section{REFERÊNCIAS}

1. Rosique J, Barbieri E. Ecologia preservar para viver. São Paulo: Cidade Nova; 1992.

2. Byers JE. Impact of non-indigenous species on natives enhanced by anthropogenic alteration of selection regimes. Oikos. 2002;97(3):449- 58.

3. Barbieri E. Biodiversidade: Capitalismo verde ou ecologia social? São Paulo: Cidade Nova; 1998.

4. Williamson M. Biological invasions. Londres: Chapman \& Hall; 1996.

5. Silva JSV, Fernandes FC, Larsen KTS, Souza RCCL. Água de lastro ameaça aos ecossistemas. Ciência Hoje. 2002;32(188):38-43.

6. Apolinário, M. Cracas invasoras no litoral brasileiro. Ciência Hoje. 2002;32(188):44-9.

7. Rossi-Wongtschowski C. A manjuba no Rio Ribeira de Iguape: biologia, comportamento e avaliação de estoque. São Paulo: IBAMA/ IOUSP/IP-SAA/SEMA; 1990.

8. Mendonça JT. A pesca na região de Cananéia SP - Brasil, nos anos de 1995 e 1996 [dissertação]. São Paulo: Instituto Oceanográfico Universidade de São Paulo; 1998.

9. Howe E, Howe C, Lim R, Burchett, M. Impact of the introduced poeciliid Gambusia holbrooki (Girard, 1859) on the growth and reproduction of Pseudomugil signifer (Kner, 1865) in Australia. Mar. Freshwater Res. 1997;48:425-434.

10. Godoi, M. R. Peixes do Brasil Sub-ordem Caracoidei Bacia do Rio Mogi Guaçu. São Paulo: Franciscana; 1975.

11. Leite, RG, Barbieri RL, Hernandez-Blazquez FJ. Morfologia do trato digestivo do curimbatá (Prochiladus scrofa) Morfometria. Bolm. do Inst. de Pesca. 1998;15(2):221-7.

12. Hilsdorf AWS. Genética e cultivo de tilápias vermelhas. Uma revisão. Bolm. do Inst. de Pesca. 1995;22(1):73-84.

13. Carlton JT. Transoceanic and interoceanic dispersal or coastal marine organisms: the biology of ballast water. Oceanography Marine Biology. Annual Review. 1985;(23):313-42.
14. Ranzani-Paiva MJT, Godinho, HM. Característica do plasma sangüíneo do pacu (Piractus mesopotamicus) HOLMBERG, 1887, em condições experimentais de criação. Bolm do Inst de Pesca. 1988;15(2):169-77.

15. Barbieri E, Melo GAS. Biodiversidade:ocorrência da espécie exótica Litopenaeus Vannamei (Boone, 1931) no complexo estuarino-lagunar de Cananéia-Iguape-Ilha Comprida. O Mundo da Saúde. 2006;30(4):654-9.

16. Margalef R. Ecologia. Barcelona: Omega; 1980.

17. Young PS. New interpretations of South American patterns of barnacle distribuition. In: Schram \& Hoeg editors. New frontiers in banacle evoluition, Rotterdam-Bookfield. Netherlands: Balkema; 1995.

18. Barbieri E. Effect of 2,4-D herbicide (2,4dichlorophenoxyacetic acid) on oxygen consumption and ammonium excretion of juveniles of Geophagus brasiliensis (Quoy \& Gaimard, 1824) (Osteichthyes, Cichlidae). Ecotoxicology. 2009;18(1):55-60.

Recebido: 06/03/2007 Received: 03/06/2007

Aprovado: $14 / 05 / 2007$ Approved: 05/14/2007 